\title{
Mesenchymal stem cells: innovative therapeutic intervention for autoimmune rheumatic diseases
}

\begin{abstract}
Mesenchymal stem cells (MSCs) are multi-potential non-hematopoietic progenitor cells capable of immuno-modulatory activities that diminish adaptive and innate immune responses. MSCs have been the object of multiple publications because their ability to regulate the immunological system and converted MSCs into a promise of developing cell therapies for various autoimmune rheumatic diseases. The present documents summarize clinical studies with efficacy and satisfactory safety profile in which MSCs have been used for cell therapies in systemic lupus erythematosus, rheumatoid arthritis and systemic sclerosis.
\end{abstract}

Keywords: mesenchymal stem cells, cell therapy, systemic lupus erythematosus, rheumatoid arthritis, systemic sclerosis

\author{
Volume 5 Issue I - 2017
}

\author{
Carolina Duarte-Salazar,' José Eugenio \\ Vázquez Meraz ${ }^{2}$ \\ 'Specialist in Rheumatology, Servicio de Reumatología, Instituto \\ Nacional de Rehabilitación, Mexico \\ ${ }^{2}$ Specialist in Hematology \& Stem Cell Transplantation, Ecatepec \\ Las Américas Blood Bank, Mexico
}

Correspondence: José Eugenio Vázquez Meraz, Specialist in Hematology, Specialist in Stem Cell Transplantation, Regional Director, Ecatepec Las Américas Blood Bank, Av. Carlos Hank González No. 8I, Col. El Salado, CP 55055 Ecatepec de Morelos, Edo. De México, México, Email euvame59@hotmail.com

Received: February 26, 2017| Published: July 25, 2017
Abbreviations: MSCs, mesenchymal stem cells; BM, bone marrow; UC, umbilical cord; AT, adipose tissue; ISCT, international society for cellular therapy; EVs, extracellular vesicles; DC, dendritic cells; SM, soluble molecules; PGE2, prostaglandin E2; TSG-6, TNF stimulated gene-6; NK, natural killer; CAF, cancer associated fibroblast; TNF, tumor necrosis factor; SLE, systemic lupus erythematosus; RA, rheumatoid arthritis; SS, systemic sclerosis; ANA, antinuclear antibodies; SLEDAI, systemic lupus erythematosus disease activity index

\section{Introduction}

Mesenchymal Stem Cells (MSCs) comprise a subgroup of nonhematopoietic stem cells of the stromal tissue that mediate a wide spectrum of immuno-regulatory activities that usually depress adaptive and innate immune responses. Their ability to regulate the immunological system has converted MSCs into a promise of developing cell therapies for the treatment of various autoimmune diseases. These cells are found virtually in every organ, initially isolated from bone marrow (BM), but can be isolated from umbilical cord (UC), adipose tissue (AT), muscle, synovia, periosteum, cartilage, lymphoid tissue, and dental pulp. ${ }^{1}$ BM derived MSCs (MSCs-BM) are scarce, constituting $<0.01 \%$ of the whole cell population of $\mathrm{BM}$, which is the main barrier to their clinical use. ${ }^{2}$ However, other alternative sites of MSCs are UC and AT, the latter can represent a promising source in which MSCs can be isolated more easily and in greater amounts. According to the definition of the International Society for Cellular Therapy (ISCT), MSCs populations are adherent cells with fibroblast-like morphology isolated from BM that lack of expression of hematopoietic markers such as CD45, CD34, CD14, CD11b, CD79, and CD19 and HLA-DR and expression of CD29, CD105, CD90 and CD73 and exhibit differentiation into osteocytes, adipocytes and chondrocytes. ${ }^{3}$ MSCs exhibit intermediate levels of molecules class I of the MHC on the cell surface and do not possess detectable levels of class II antigens of the MHC, principally HLADR, nor of co-stimulatory molecules CD40, CD80, and CD86. Such low immunogenicity allows MSCs to be an appropriate source of cells for allogenic transplantation, ${ }^{4}$ explaining why allogenic MSCs may be safely infused to patients without side effects.

\section{Immune regulation mechanisms of MSCs}

The mechanisms by which MSCs carry out their immunomodulation function are through cell-to-cell contact, through a structure called MSCs secretome, which includes soluble molecules (SM) and extracellular vesicles (EVs) released by MSCs into the milieu. ${ }^{5,6}$ The SM mediating immunoregulatory tasks of MSCs are abundant and include indoleamine 2,3-dioxygenase (IDO), prostaglandin E2 (PGE2), soluble HLA-G5 (sHLA-G5), IL-10, TGF- $\beta 1$, nitric oxide, heme oxigenase-1 (HO-1) and TNF stimulated gene-6 (TSG6). ${ }^{7,8}$ These immunoregulatory molecules of MSCs can interact with immunological cells, generating a suppressor response toward T cells, B cells, dendritic cells (DC), macrophages and natural killer (NK). ${ }^{9} 10$ EVs are subcellular particles of different size comprising exosomes, which originates from multivesicular bodies; these microvesicles are fragments of cell surface membrane and apoptotic bodies. Exosomes are composed of a double layer lipid membrane and inside proteins, lipids and RNAs and, microvesicles are plenty of proteins and lipids. ${ }^{11}$ EVs can fuse with the surface membrane of adjacent cells and discharge their content, promoting or regulating functional changes in target cells. ${ }^{12}$ Exosomes can participate in various diseases notably remodeling the tumor environment by cancer associated fibroblast (CAF) generation, neo-angiogenesis, tumor proliferation and metastasis. ${ }^{13}$

MSCs are capable of regulating both adaptive and innate immunity through these immuno-regulatory molecules. The principal immunoregulatory effects of MSCs are exerted in adaptive immunity to T cells as follows:

\section{i. Promote survival of T-cells in a quiescent state ${ }^{14}$}

ii. Induce division arrest and energy of activated $\mathrm{T}$ cells, accumulating $\mathrm{T}$ cells in the G0/G1 cell-cycle phase ${ }^{15}$

iii. Inhibit T-cell proliferation ${ }^{16}$ 
iv. Diminish cytotoxicity mediated by CD8+ cytotoxic T cells ${ }^{17}$ and

v. Promote the production of $\mathrm{T}$ regs cells $\mathrm{CD} 4+$ and $\mathrm{CD} 25+$, potent immune-suppressor cells that aid in maintaining homeostasis and tolerance to their own antigens ${ }^{18,19}$

MSCs also act on B cells inhibiting their proliferation, differentiation and activation, with a limited production of immunoglobulins. This effect is also mediated by T cells ${ }^{19,20}$ (Figure1). On the other hand, in the innate immunity system, there is the participation of mature DC $(\mathrm{mDC})$, which plays a primordial role in the presentation of naive T-cell antigens. It has been demonstrated that mesenchymal cells interfere with DC function in the presentation of antigens through diminishing the expression of class II molecules and co-stimulatory molecules, as well as the decrease of the production of IL-12, whose main action is that of promoting the differentiation of naive helper $\mathrm{T}$ cells into the Th1 subgroup for IFN gamma production. ${ }^{21,22}$ Additionally, MSCs down-regulate the proinflammatory potential of DC on inhibiting tumor necrosis factor (TNF) production. ${ }^{17}$ On the other hand, plasmacytoid DC (pDC), a rare DC subtype, are specialized cells that express Toll-like receptors 7 and 9, which permit the detection of viral and bacterial nucleic acids. These cells produce great amounts of type I IFN in response to the microbial stimulus; however, the production of IL-10 increased when these cells are incubated with MSCs. ${ }^{23}$ MSCs suppress the effector functions of neutrophils and NK cells and, modify monocyte differentiation toward an anti-inflammatory phenotype, inducing macrophage 2 (M2). ${ }^{24}$ This interaction between MSCs and immune system, both adaptive and innate system, generates regulatory effects on immune cells, rendering MSCs as an interesting and potential therapy in autoimmune disorders (Figure 1). The purpose of this review is to present clinical studies with clinical efficacy and satisfactory safety profile of MSCs in autoimmune rheumatic diseases such as Systemic Lupus Erythematosus (SLE), Rheumatoid Arthritis (RA) and Systemic Sclerosis (SS).

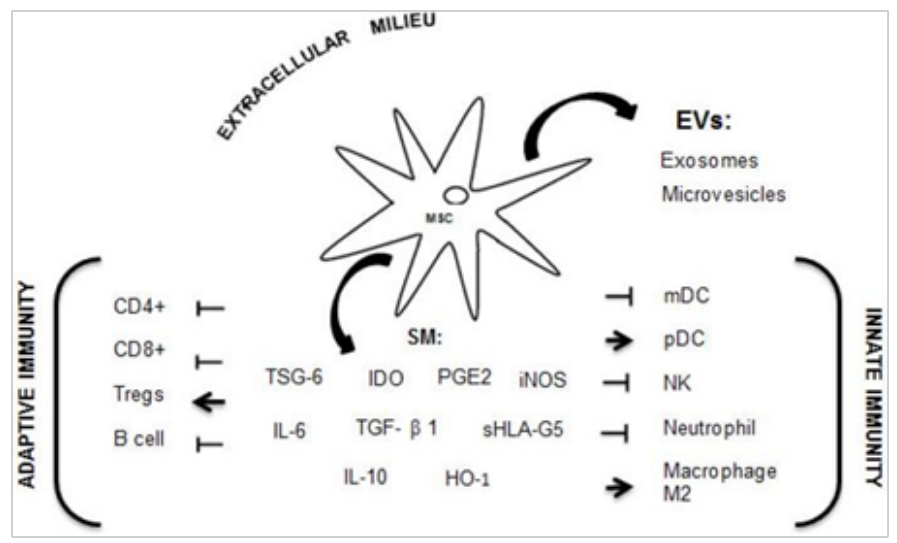

Figure I Mechanism of immunomodulation through MSCs releasing soluble molecules (SM) and EVs (extracellular vesicles) interacting with immunological cells from adaptive and innate systems.

\section{Systemic lupus erythematosus}

Current therapies are rarely curative in patients with severe forms of this autoimmune disease. In SLE, conventional treatment with corticosteroids and immunosuppressors or with biological agents, have improved the outcome in these patients. ${ }^{25}$ However, there is a subgroup of patients with important mortality and morbidity who do not respond to medical treatment, reporting a mortality of up to $10 \%$ at 10years. ${ }^{26}$ Scientific evidence revealed that MSCs-BM in animal models as well as in patients with SLE present deterioration in their capacity of proliferation, differentiation and secretion of cytokines, as well as their immunomodulatory mechanisms. The MSCs-BM of patients with SLE exhibit early signs of senescence, observing flat and larger mesenchymal cells with slow growth in cell cultures as compared with that of control MSCs. ${ }^{27}$ They also show a reduced ability for producing $\mathrm{T}$ regs cells ${ }^{28}$ and an increase in the proportion of MSCs apoptosis. ${ }^{29}$

From 2010 to the present, have been reported in the literature 280 SLE patients refractory to conventional treatment and treated with $\mathrm{MSCs}^{30}$ predominantly with severe lupus nephritis. Consequently, SLE was attenuated reducing clinical manifestations, stabilization of renal damage and improvement in serological markers (Table 1). Initially, autologous MSCs-BM efficacy and safety were evaluated in two patients with SLE, observing an important increase in $\mathrm{T}$ regs cells, without improvement in clinical manifestations. ${ }^{31}$ Another report, published 15 patients with SLE with predominance of renal activity; the patients received an intravenous infusion of $1 \times 10^{6} \mathrm{cells} /$ $\mathrm{kg}$ of allogenic BM-derived MSCs. At 12 months of follow-up, Systemic Lupus Erythematosus Activity Index (SLEDAI) scores diminished from $12.2 \pm 3.3$ to $3.2 \pm 2.8$, proteinuria from $2,505 \pm 1,323$ to $858 \pm 800 \mathrm{mg} / 24 \mathrm{~h}$, and a reduction in anti-double-stranded DNA (dsDNA) levels. ${ }^{32}$ In 16patients, allogenic UC-derived MSCs were infused in patients with lupus nephritis; these patients were administered $1 \times 10^{6}$ cells $/ \mathrm{kg}$. SLEDAI scores diminished significantly one month after infusion with MSCs-UC, $18.4 \pm 1.1$ vs. $10.8 \pm 0.8$, the scores continuing to improve after the third month. Proteinuria, antidsDNA antibodies, and antinuclear antibodies (ANA) diminished from the third month on, while T regs cells increased..$^{33}$ Alveolar pulmonary hemorrhage and hematological abnormalities, that compromise life were treated with MSCs-UC and MSC-BM respectively. All patients presented improvement at one month. ${ }^{34,35}$ From the same research group, Wang D et al. ${ }^{36}$ included 87 patients with refractory SLE with a risk of organ failure; these patients received an infusion of MSCs-BM of allogenic UC at a dose of $1 \times 10^{6} \mathrm{cells} / \mathrm{kg}$. The authors reported $28 \%$ of patients in complete remission at 1year; $31 \%$ at 2 years, $42 \%$ at $3 y e a r s$ and $50 \%$ at 4 years. Frequency of relapse was $12 \%$ at 1 year, $18 \%$ a 2 years and $17 \%$ at 3 and $4 y^{2}$ ars $^{36}$ and $\mathrm{Gu}$ et al. ${ }^{37}$ utilized the MSCs BM of relatives in 81 patients with lupus neprhirtis, reporting complete remission in $60 \%$ of patients, with an important decreased in the SLEDAI score, an increase in glomerular filtration, and reduction of the dose of prednisone, cyclophosphamide, and mycophenolate mofetil. ${ }^{37}$ More recently, in a study to evaluate the safety and efficacy of MSCs-UC in patients with active SLE, the patients received an infusion of $1 \times 10^{6} \mathrm{cells} / \mathrm{kg}$ on days 1 and 7 . The results were the following: $60 \%$ with complete or partial response during a 1-year follow-up. Seven patients presented relapse after 6 months. The baseline SLEDAI score was $10.83 \pm 4.63$, while the final SLEDAI score was $6.4 \pm 3.5$, with diminution of anti-dsDNA and ANA with normalization of $\mathrm{C} 3 .^{38}$ Thus, these data indicate that treatment with allogenic BM or UC-derived MSCs in a subgroup of patients with SLE who do not respond to conventional treatment demonstrated significant reduction in disease activity and improvement in immunological parameters. In comparison the first study reported on two patients with SLE in which autologous MCSs were utilized did not demonstrate clinical benefits. ${ }^{31}$ This initial information strongly suggests that transplantation with allogenic MSCs of BM and/or UC nor autologous can provide an important benefit in patients with this autoimmune disease. 
Table I Outcome of 280 SLE patients treated with mesenchymal stem cells (MSCs)

\begin{tabular}{|c|c|c|c|c|c|}
\hline Author & $\begin{array}{l}\text { No. of } \\
\text { patients }\end{array}$ & $\begin{array}{l}\text { Clinical } \\
\text { manifestation }\end{array}$ & $\begin{array}{l}\text { Origin of } \\
\text { MSCs }\end{array}$ & Outcome & $\begin{array}{l}\text { Follow Up } \\
\text { (months) }\end{array}$ \\
\hline Carrion et al. ${ }^{31}$ & 2 & $\begin{array}{l}\text { Heterogeneous } \\
\text { clinical characteristics }\end{array}$ & Autologous BM & Increased T regs cells. No clinical improvement & 14 \\
\hline Lian et al. ${ }^{32}$ & 15 & Nefritis & Allogenic BM & Decreased proteinuria, SLEDAI and anti-dsDNA & 12 \\
\hline Sun et al. ${ }^{33}$ & 16 & Nefritis & Allogenic UC & $\begin{array}{l}\text { Decreased proteinuria, SLEDAl, anti-dsDNA and AAN, } \\
\text { increased T reg cells }\end{array}$ & 8 \\
\hline Shi et al. ${ }^{34}$ & 4 & $\begin{array}{l}\text { Alveolar pulmonary } \\
\text { hemorrhage }\end{array}$ & Allogenic UC & $\begin{array}{l}\text { Increased hemoglobin,serum albumin and } \mathrm{O} 2 \text { saturation. } \\
\text { Normal Tomography }\end{array}$ & 6 \\
\hline Li et al. ${ }^{35}$ & 35 & Cytopenias & $\begin{array}{l}\text { Allogenic BM } \\
\text { or allogenic UC }\end{array}$ & $\begin{array}{l}\text { Increased hemoglobin, leucocytes and platelets, Decreased } \\
\text { disease activity. Increased T regs cells and decreased Th I } 7\end{array}$ & 21 \\
\hline Wan et al..$^{36}$ & 87 & $\begin{array}{l}\text { Heterogeneous } \\
\text { clinical characteristics }\end{array}$ & $\begin{array}{l}\text { Allogenic BM } \\
\text { or allogenic UC }\end{array}$ & Clinical remission $28 \%$ at one year & 27 \\
\hline Gu et al. ${ }^{37}$ & 81 & Nefritis & $\begin{array}{l}\text { Allogenic BM } \\
\text { or allogenic UC }\end{array}$ & Renal remission $60 \%$ & 12 \\
\hline Wang et al. ${ }^{38}$ & 40 & Nefritis & UC-allogenic & Complete clinical remission $32 \%$ Partial remission $28 \%$ & 12 \\
\hline
\end{tabular}

\section{Rheumatoid arthritis (RA)}

RA is a chronic autoimmune inflammatory joint disease characterized by synovial hyperplasia and joint damage leading significant disability. Current treatment strategies do not arrest cartilage and bone damage in spite of clinical remission. MSCs have immunomodulatory and tissue repair properties and, their use in RA is being explored. In RA allogenic MSCs were used with clinical improvement but no more than few months suggesting that cell therapy in RA would require repeated infusions. Since 2012, almost 200 patients with refractory RA were treated with $\mathrm{MSCs}^{39-41}$ All treated patients had clinical improvements with no serious adverse effects reported (Table 2).

Table 2 Outcome of I86 RA patients treated with mesenchymal stem cells (MSCs)

\begin{tabular}{|c|c|c|c|c|c|c|}
\hline Author & $\begin{array}{l}\text { No. of } \\
\text { patients }\end{array}$ & $\begin{array}{l}\text { Clinical } \\
\text { manifestation }\end{array}$ & $\begin{array}{l}\text { Origin of } \\
\text { MSCs }\end{array}$ & Outcome & $\begin{array}{l}\text { Follow Up } \\
\text { (months) }\end{array}$ & Other conditions \\
\hline Liang et al. ${ }^{39}$ & 4 & $\begin{array}{l}\text { Refractory } \\
\text { arthritis }\end{array}$ & $\begin{array}{l}\text { Allogenic BM } \\
\text { and UC }\end{array}$ & Reduced DAS 28 and VAS pain score & 19 & $\begin{array}{l}\text { No immunological } \\
\text { parameters were done }\end{array}$ \\
\hline Wang et al. ${ }^{40}$ & 136 & $\begin{array}{l}\text { Refractory } \\
\text { arthritis }\end{array}$ & Allogenic UC & $\begin{array}{l}\text { Improved DAS } 28 \text { and HAQ Increased T } \\
\text { regs cells. Decreased IL- } 6 \text { and TNF-alfa }\end{array}$ & 8 & Repeated infusions \\
\hline $\begin{array}{l}\text { García } \\
\text { Álvaroet al. }{ }^{41}\end{array}$ & 46 & $\begin{array}{l}\text { Refractory } \\
\text { arthritis }\end{array}$ & Allogenic AT & $\begin{array}{l}\text { Approximately } 30 \% \text { of each group with } \\
\text { ACR } 20 \text { at one month. After } 3 \text { months } \\
\text { no clinical benefit }\end{array}$ & 6 & $\begin{array}{l}\text { Repeated infusions } \\
\text { with different doses of } \\
\text { MSCs }\end{array}$ \\
\hline
\end{tabular}

\section{Sclerosis systemic (SS)}

SS is a disease characterized by early vascular endothelial damage, consequently with an increase in collagen synthesis and progressive fibrosis of the skin and internal organs. This autoimmune disease exhibits a mortality ranging between 30 and $50 \%$ during the first 5years. ${ }^{42}$ At present, there is no treatment that is useful in SS, except for autologous hematopoietic cell transplantation, which evidences greater therapeutic benefit and an increase in survival in comparison with treatment with monthly dosages of cyclophosphamide. ${ }^{43}$ Considering the pleiotropic effects of MSCs with immunoregulation, angiogenic and anti-fibrotic capacities, these cells can represent an opportunity in this intractable disease. Scientific data demonstrates that MSCs-BM in patients with SS present deterioration in their immunomodulatory mechanisms. The MSCs-BM of patients with SS demonstrates premature senescence; however, they retain suppressor functions and a normal ability to generate functional $\mathrm{T}$ regs cells. ${ }^{44}$ Recently, it was demonstrated a significant increase of transforming growth factor (TGF)- $\beta$ receptor type II in the mesenchymal cells of patients with SS compared with mesenchymal cells of healthy donors. This increase associated with an activation of TGF- $\beta$, generates an increase in the synthesis of the gene that encodes type I collagen, thus, an excessive production of type I collagen is unfavorable in this disease. ${ }^{45}$ These findings show that the mesenchymal cells of patients with SS are defective in certain functions; therefore, the use of the allogenic MCSs of healthy individuals is justified in these patients.

In 2008, Christopeit et al. ${ }^{46}$ reported important improvement in a female patient with refractory SS at post-transplantation of MSCs-BM of a related haploidentical allogenic donor. The infusion of MSCs was associated during the following 3 months with cicatrization of the digital ulcers at six months with improved blood flow in the fingers and an increase of partial transcutaneous oxygen pressure; as well as improvement in the score of skin measurement according to the Rodnan scale (11 vs. 25points), but without changes in immunological parameters. ${ }^{46}$ In 2011, this same study group reported five additional cases of patients with this disease treated with allogenic MSCs-BM. These patients exhibited fibrosis of the skin (5/5), interstitial pulmonary disease (4/5), vasculopathy $(5 / 5)$, cardiomyopathy (4/5), and myopathy (2/5). At 18 months of followup, $4 / 5$ of the patients improved in skin thickness, in digital ulcers, or in limb necrosis. ${ }^{47}$ Limb revascularization was reported in a patient with SS after autologous MSCs-BM infusion. ${ }^{48}$ More recently, in a phase I study, the safety of autologous MSCs-AT was demonstrated 
in patients with severe lower-limb ischemia without the possibility of revascularization, exhibiting an increase in transcutaneous oxygen pressure and leg ulcer cicatrization. ${ }^{49}$ Local injections of autologous MSCs of peripheral blood and BM have been utilized, reporting an improvement in the Raynaud phenomenon and of digital-ulcer and lower-limb cicatrization. ${ }^{50}$ Autologous MSCs-AT have been employed in local injection of areas localized of the face, with a reduction of skin thickness. ${ }^{51}$ and in that of the fingers, with important improvement of the disability, of the edema and of the Raynaud phenomenon. ${ }^{52}$

\section{Conclusion}

Despite that knowledge remains limited, clinical studies suggest that these MSCs, due to their immunomodulatory properties, can be relevant in the treatment of autoimmune clinical conditions that compromise life, such as SLE, RA and RA. Additionally, MSCs presents an adequate safety profile in terms of their administration, because adverse serious events attributed to their administration have not been reported in these diseases. The immunoregulation capacity of MSCs confers to these cells a very promising therapy in these autoimmune rheumatic diseases. These data justify considering MSCs as an innovative therapy. Finally, it is indispensable for long term studies to be performed to determine whether these immunomodulators effects of MSCs are transient or long-lasting.

\section{Acknowledgements}

None.

\section{Conflict of interest}

The author declares no conflict of interest.

\section{References}

1. Da Silva Meirelles L, Chagastelles PC, Nardi NB. Mesenchymal stem cells reside in virtually all post natal organs and tissues. $J$ Cell Sci. 2006;119(Pt 11):2204-2213.

2. Kolf CM, Cho E, Tuan RS. Mesenchymal stromal cells. Biology of adult mesenchymal stem cells:regulation of niche, self-renewal and differentiation. Arthritis Res Ther. 2007;9(1):204.

3. Dominici M, Le Blanc K, Mueller I, et al. Minimal criteria for defining multipotent mesenchymal stromal cells. The International Society for Cellular Therapy position statement. Cytotherapy. 2006;8(4):315-317.

4. Le Blanc K, Tammik C, Rosendahl K, et al. HLA expression and immunologic properties of differentiated and undifferentiated mesenchymal stem cells. Exp Hematol. 2003;31(10):890-896.

5. Bruno S, Deregibus MC, Camussi G. The secretome of mesenchymal stromal cells: role of extracellular vesicles in immunomodulation. Immunol Lett. 2015;168(2):154-158.

6. Heldring N, Mäger I, Wood MJ, et al. Therapeutic potential of multipotent mesenchymal stromal cells and their extracellular vesicles. Hum Gene Ther. 2015;26(8):506-517.

7. Keating A. Mesenchymal stromal cells: new directions. Cell Stem Cell. 2012;10(6):709-716.

8. Bernardo ME, Fibbe WE. Mesenchymal stromal cells: sensors and switchers of inflammation. Cell Stem Cell. 2013;13(4):392-402.

9. Han Z, Jing Y, Zhang S, et al. The role of immunosuppression of mesenchymal stem cells in tissue repair and tumor growth. Cell Biosci. 2012;2(1):8.

10. Tyndall A. Mesenchymal stem cell treatments in rheumatology: a glass half full? Nat Rev Rheumatol. 2014;10(2):117-124.
11. Maas SL, Breakefield XO, Weaver AM. Extracellular vesicles: unique intercellular delivery vehicles. Trends Cell Biol. 2017;27(3):172-188.

12. Pitt JM, Kroemer G, Zitvogel L. Extracellular vesicles: masters of intercellular communication and potential clinical interventions. $J$ Clin Invest. 2016;126(4):1139-1143.

13. Pistoia V, Raffaghello L. Mesenchymal stromalcells and autoimmunity. Int Immunol. 2017;29(2):49-58.

14. Benvenuto F, Ferrari S, Gerdoni E, et al. Human mesenchymal stem cells promote survival of $\mathrm{T}$ cells in a quiescent state. Stem Cells. 2007;25(7):1753-1760.

15. Glennie S, Soeiro I, Dyson PJ, et al. Bone marrow mesenchymal stem cells induce division arrest anergy of activated T cells. Blood. 2005;105(7):2821-2827.

16. Beyth S, Borovsky Z, Mevorach D, et al. Human mesenchymal stem cells alter antigen-presenting cell maturation and induce T-cell unresponsiveness. Blood. 2005;105(5):2214-2219.

17. Uccelli A, Moretta L, Pistoia V. Mesenchymal stem cells in health and disease. Nat Rev Immunol. 2008;8(9):726-736.

18. Maccario R, Podestà $\mathrm{M}$, Moretta $\mathrm{A}$, et al. Interaction of human mesencymal stem cells with cells involved in alloantigen-specific immune response favors the diffrentitation of $\mathrm{CD} 4+$ subsets expressing a regulatory/suppressive phenotype. Haematologica. 2005;90(4):516-525.

19. Rosado MM, Bernardo ME, Scarsella M, et al. Inhibition of B cell proliferation and antibody production by mesenchymal stromal cells is mediated by T cells. Stem Cells Dev. 2015;24(1):93-103.

20. Corcione A, Benvenuto F, Ferretti E, et al. Human mesenchymal stem cells modulate B cell functions. Blood. 2006;107(1):367-372.

21. Ramasamy R, Fazekasova H, Lam EW, et al. Mesenchymal stem cells inhibit dendritic cell differentiation and function by preventing entry into the cell cycle. Transplantation. 2007;83(1):71-76.

22. Beyth S, Borovsky Z, Mevorach D, et al. Human mesenchymal stem cells alter antigen-presenting cell maturation and induce T-cell unresponsiveness. Blood. 2005;105(5):2214-2219.

23. Aggarwal S, Pittenger MF. Human mesenchymal stem cells modulate allogenic immune cell responses. Blood. 2005;105(4):1815-1822.

24. Le Blanc K, Mougiakakos D. Multipotent mesenchymal stromal cells and the innate immune system. Nat Rev Immunol. 2012;12(5):383-396.

25. Crow MK. Developments in the clinical understanding of lupus. Arthritis Res Ther. 2009;11(5):245.

26. Doria A, Gatto M, Zen M, et al. Optimizing outcome in SLE: treating to target and definition of treatment goals. Autoimmun Rev. 2014;13(7):770777.

27. Nie Y, Lau C, Lie A, et al. Defective phenotype of mesenchymal stem cells in patients with systemic lupus erythematosus. Lupus. 2010;19(7):850-859.

28. Gu Z, Cao X, Jiang J, et al. Upregulation of p16INK4A promotes cellular senescence of bone marrow-derived mesenchymal stem cells from systemic lupus erythematosus patients. Cell Signal. 2012;24(12):23072314.

29. Li X, Liu L, Meng D, et al. Enhanced apoptosis and senescence of bone marrow-derived mesenchymal stem cells in patients with systemic lupus erythematosus. Stem Cells Dev. 2012;21(13):2387-2394.

30. Tyndall A, van Laar JM. Stem cell transplantation and mesenchymal cells to treat autoimmune diseases. Presse Med. 2016;45(6 Pt 2):e159-169.

31. Carrion F, Nova E, Ruiz C, et al. Autologous mesenchymal stem cell treatiment increased $\mathrm{T}$ regulatory cells with no effect on disease activity in two systemic lupus erythematosus patients. Lupus. 2010;19(3):317322 . 
32. Liang J, Zhang H, Hua B, et al. Allogenic mesenchymal stem cells transplantation in refractory systemic lupus erythematosus: a pilot clinical study. Ann Rheum Dis. 2010;69(8):1423-1429.

33. Sun L, Wang D, Liang J, et al. Umbilical cord mesenchymal stem cell transplantation in severe and refractory systemic lupus erythematosus. Arthritis Rheum. 2010;62(8):2467-2475.

34. Shi D, Wang D, Li X, et al. Allogenic transplantation of umbilical cordderived mesenchymal stem cells for diffuse alveolar hemorrhage in systemic lupus erythematosus. Clin Rheumatol. 2012;31(5):841-846.

35. Li X, Wang D, Liang J, et al. Mesenchymal SCT ameliorates refractory cytopenia in patients with systemic lupus erythematosus. Bone Marrow Transplant. 2013;48(4):544-550.

36. Wang D, Zhang H, Liang J, et al. Allogenic mesenchymal stem cell transplantation in severe and refractory systemic lupus erythematosus: 4 years of experience. Cell Transplant. 2013;22(12):2267-2277.

37. Gu F, Wang D, Zhang H, et al. Allogenic mesenchymal stem cell transplantation for lupus nephritis patients refractory to conventional therapy. Clin Rheumatol. 2014;33(11):1611-1619.

38. Wang D, Li J, Zhang Y, et al. Umbilical cord mesenchymal stem transplantation in active and refractory systemic lupus erythematosus: a multicenter clinical study. Arthritis Res Ther. 2014;16(2):R79.

39. Liang J, Li X, Zhang H, et al. Allogenic mesenchymal stem cells transplantation in patients with refractory RA. Clin Rheumatol. 2012;31(1):157-161

40. Wang L, Wang L, Cong X, et al. Human umbilical cord mesenchymal stem cell therapy for patients with active rheumatoid arthritis: safety and efficacy. Stem Cells Dev. 2013;22(24):3192-3202.

41. Álvaro-Gracia JM, Jover JA, García-Vicuña R, et al. Intravenous administration of expanded allogenic adipose-derived mesenchymal stem cells in refractory rheumatoid arthritis (Cx611): results of a multicenter, dose escalation, randomised, single-blind, placebo-controlled phase Ib/ IIa clinical trial. Ann Rheum Dis. 2017;76(1):196-202.

42. Fransen J, Popa-Diaconu D, Hesselstrand R, et. al. Clinical prediction of 5-year survival in systemic sclerosis: validation of a simple prognostic model in EUSTAR Centres. Ann Rheum Dis. 2011;70(10):1788-1792.
43. van Laar JM, Farge D, Sont JK, et al. Autologous hematopoietic stem cell transplantation vs intravenous pulse cyclophosphamide in diffuse cutaneous systemic sclerosis: a randomized clinical trial. JAMA. 2014;311(24):2490-2498.

44. Cipriani P, Di Benedetto P, Liakouli V, et al. Mesenchymal stem cells (MSCs) from scleroderma patients (SSc) preserve their immonomodulatory properties although senescent and normally induce T regulatory cells (Tregs) with a functional phenotype implications for cellular-based therapy. Clin Exp Immunol. 2013;173(2):195-206.

45. Vanneaux V, Farge-Bancel D, Lecourt S, et al. Expression of transforming growth factor beta receptor II in mesenchymal styem cells from systemic sclerosis patients. BMJ Open. 2013;3(1):e001890.

46. Christopeit M, Schendel M, Föll J, et al. Marked improvement of severe progressive systemic sclerosis after transplantation of mesenchymal stem cells from an allogenic haploidentical-related donor mediated by ligation of CD137L. Leukemia. 2008;22(5):1062-1064.

47. Keyszer G, Christopeit M, Fick S, et al. Treatment of severe progressive systemic sclerosis with transplantation of mesenchymal stromal cells from allogenic related donors: report of five cases. Arthritis Rheum. 2011;63(8):2540-2542.

48. Guiducci S, Porta F, Saccardi R, et al. Autologous mesenchymal stem cells foster revascularization of ischemic limbs in systemic sclerosis. A case report. Ann Intern Med. 2010;153(10):650-654.

49. Bura A, Planat-Benard V, Bourin P, et al. Phase I trial: the use of autologous cultured adipose-derived stroma/stem cells to treat patients with non-revascularizable critical limb ischemia. Cytotherapy. 2014;16(2):245-257.

50. Nevskaya T, Ananieva L, Bykovskaia S, et al. Autologous progenitor cell implantation as a novel therapeutic intervention for ischemic digits in systemic sclerosis. Rheumatology (Oxford). 2009;48(1):61-64.

51. Scuderi N, Ceccarelli S, Onesti MG, et al. Human adipose-derived stromal cells for cell-based therapies in the treatment of systemic sclerosis. Cell Transplant. 2013;22(5):779-795.

52. Granel B, Daumas A, Jouve E, et al. Safety, tolerability and potential efficacy of injection of autologous adipose-derived stromal vascular fraction in the fingers of patients with systemic sclerosis: an open-label phase I trial. Ann Rheum Dis. 2015;74(12):2175-2182. 